\title{
Estimation of Age from spheno-occipital synchondrosis closure using computed tomography in Yemen
}

\begin{abstract}
Background: The spheno-occipital synchondrosis was chosen as an age marker of interest since past researches suggested that there is considerable variation in the time of closure which required further investigation. In order to obtain the most accurate estimations of age population specific data are required.
\end{abstract}

Objective: The aim of the present study was to determine the chronology and pattern of union of the spheno-occipital synchondrosis among Yemeni subjects using CT scanning to assess if this age marker is a useful tool for age estimation.

Subjects and Methods: In this cross-sectional study, a sample of 217 subjects of both sexes whose ages ranged between 15 and 25years was examined. The studied group was formed of 121 males and 96 females. The state of fusion of the SOS or basilar synchondrosis was examined as a biological age indicator using a high resolution multi-slice CT scans of the head.

Results: Mean ages of open, semi-closed, closed sutures with scar and closed sutures without scar were 16, 18, 21.32 and 21.78years in males, and 15, 20, 21.56 and 20.41 in females, respectively. Complete fusion was seen at 16 years old or above in males and 15 years old or above in females. Spearman's correlation ratio coefficient showed a linear correlation between age and suture situation in both sexes $(\mathrm{p}<0.000 *$ for both and rho $=0.509 \& 0.080$ for males and females, respectively).

Conclusion: Our findings indicated that the stage of fusion of the spheno-occipital synchondrosis using computed tomography could be a useful forensic tool to determine age in both sexes in Yemen population.

Keywords: age estimation, spheno-occipital synchondrosis, computed tomography, yemen
Volume I Issue I - 2015

\section{Usama M Ibrahim El Barrany, Manal Mohy El din Ismail, Mohamed Adly Mohamed and Mokhtar Ahmed Alhrani}

Forensic Medicine \& Clinical Toxicology Department, Cairo University, Egypt

Correspondence: Usama M Ibrahim El Barrany, Forensic Medicine \& Clinical Toxicology Department, Cairo University, Mehawelat street, Pyramids, Giza, Egypt, Tel +20 I 14409 I I 16, Email ualbarrany@yahoo.com

Received: June 07, 2015 | Published: July 25, 2015

\section{Introduction}

Estimation of age is one of the important factors that help in identification. The determination of age is needed for employment, marriage, majority, management of property, voting right, competency as witness and testamentary capacity. The significance of determination of the age is most important in the criminal cases, such as rape, infanticide, kidnapping, prostitution, juvenile delinquency and criminal responsibility. ${ }^{1}$ There has been increasing interest in the study of skeletal age markers in recentyears due to growing pressure on forensic practitioners to provide more accurate age estimations. ${ }^{2}$ Determination of the age of individuals from bones is one crucial step in forensic medicine. Numerous studies over the past century have been conducted to assess the accuracy of qualitative and quantitative observations for estimating bone age. As complete dependence on one bone to determine individual's age is not so reliable, it has become necessary to develop techniques for age estimation from as many different bones bearing age markers as possible. ${ }^{3}$ In general, estimating the age is problematic because of human variability in the growth and aging processes. Analysis of errors associated with skeletal age estimation methods is necessary so that the performance of these methods is not overestimated and the uncertainty of these skeletal techniques can be quantified and better understood. ${ }^{4}$ According to Iscan $Y,{ }^{5}$ nearly every bone contains an age marker, but it is important that we "know where to look and how to recognize and interpret them." This pursuit to properly interpret which areas of the skeleton exhibit morphological changes with age has been immense. Some of the most well-documented and utilized age indicators include cranial suture closure, dentition, epiphyses and ossification centers, and the articulating surfaces of the ox coxae (pubic symphyses and auricular surface). Below the age of 14-15years, the developing dentition and hand/wrist ossification provide reasonably accurate age estimations but, once these development sites have completed growth, accurate age estimation becomes far more difficult. Determination of adult or adolescent status of an unknown age individual is difficult due to the paucity of skeletal and dental age markers available around this age; the only readily examinable markers being the $3 \mathrm{rd}$ molar tooth and the medial clavicular epiphysis, both of which display considerable variation in development. ${ }^{2}$ One of these indicators that have been advocated as a good age indicator is the state of fusion of the spheno-occipital synchondrosis, although there are different ideas about its reliability. ${ }^{6}$ Recent developments in technology, however, have streamlined the ability to collect and analyze data and open the door for new and more accurate methods to be created. Though such technologies were not developed specifically for forensic or anthropological investigation, their extended application has been very useful. For instance, X-rays, CT scans and MRI primarily used in the field of diagnostic medicine, have now become tools in anthropological investigation. ${ }^{7}$ In Yemen, a reliable documentation of 
birth certificates is lacking furthermore, this is particularly the case with the increasing numbers of undocumented individuals moving across international borders resulting in the need to determine the age status of many of these people; particularly around the adolescent/ adult cut-off point of 18years, an important legal demarcation in many jurisdictions. The current research is an endeavor to establish a new quantitative method in Yemen to study the closure of one of the most important cranial sutures, which can address continuous variability more adequately, using computed tomography. The goals of this study are to determine the sequence and timing of closure of the spheno-occipital synchondrosis among Yemeni subjects using CT scanning and to assess if this radiological tool is a useful method for age estimation for individuals around the age of 18years and then, to construct a specific regression analysis equation for Yemen population.

\section{Subjects and methods}

\section{Study design}

This is a cross-sectional study of the relationship between sphenooccipital synchondrosis closure and chronological age.

\section{Sample}

The study population consisted of a random sample of Yemen society. A sample of 217 High resolution multi-slice CT scans of the head was evaluated to determine the ossification stage of the sphenooccipital synchondrosis in individuals aged from 15 to 25 years with verified dates of birth. The studied group was formed of 121 males and 96 females. Most images were obtained for clinical purposes from consecutive patients, with known dates of birth and who have attended the Department of Radiology of University of Science \& Technology (UST) Hospital (Yemen) between January and October 2012. In each case, the identification number, gender and date of birth of the person, the date of the examination and the ossification status of the spheno-occipital synchondrosis were recorded. The reminder of subjects in the same age group (between 15 and 25years) were taken from schools and colleges of Sana'a; the capital of Yemen. The date of birth of the subjects was confirmed from birth certificates, early childhood immunization records or passport. The chronological age was calculated by subtracting the date of birth from the date of the radiological examination. The individuals who were born in other governorates and residing in Sana'a will be also included in the study. Subjects of different geographical locations, climates and socioeconomic status will be included in the study, but no attempt has been made at this stage to categorize individuals according to residence or socio-economic status, although this is the subject of future research. Clinical examination (anthropometric criteria, signs of sexual maturation) and odontological examination will be done. The main criterion considered in the study for forensic age determination in the relevant age group based on odontological examination is tooth eruption. Tooth eruption means the gingival emergence of the crown of the tooth. It is diagnosed by inspecting the oral cavity of the person concerned; no X-ray is required. Clinical examination was done just to exclude any abnormalities in growth that may alter bone age. The study was conducted in accordance with the ethical standards laid down by the Declaration of Helsinki (Finland). The World Medical Association developed the Declaration of Helsinki as a statement of ethical principles for medical research involving human subjects, including research on identifiable human material and data.

\section{Inclusion \& exclusion criteria}

Individuals of unknown age or those who had suffered significant head trauma which potentially affected the area of interest were excluded from the sample. Individuals with endocrine diseases, metabolic, nutritional disorders, systemic chondroosseous disease, or underlying bone pathology (such as punched-out lesion or internal frontal hyperostosis) were excluded from the sample. All examinations regarding traumatologic or neoplastic changes were not included in the sample, although indications were not statistically evaluated. All examinations with poor image quality were also excluded.

\section{Radiographic staging}

The degree of SOS closure was classified in many literatures into different grades by measurement or assessment of the length of the suture itself. In our study the ossification stages of the spheno-occipital synchondrosis were defined using a four stage system modified from that developed by, ${ }^{2}$ the stages are as follows:

Stage1: Completely open

Stage2: Closed superior border.

Stage3: Complete fusion with a visible fusion scar

Stage4: Complete fusion with no visible fusion scar

\section{Radiographic measurement}

All CT data were acquired on High resolution multi-slice CT scanner, on osseous window (Brilliance 64). The imaging system utilised at the (UST) Hospital is a Siemens SOMATOM $\mathbb{}$ DEFINITION AS multi slice scanner (Global Siemens Healthcare Headquarters, Germany), with the following protocol: 120kvp, $64-175 \mathrm{mAs}$, collismation, $16 \times 0.625$; rotation time 0.28 seconds; pitch 0.683 ; section slice $4.8 \mathrm{~m}$, Number of slices $2 \times 128$, Isotropic resolution $0.33 \mathrm{~mm}$, temporal resolution $75 \mathrm{~ms}$ ). The images are then reconstructed and viewed on the scanner's workstation using the Siemens software package.

\section{Statistical analysis}

All the images were staged by one observer. After 1 month, 30 images were randomly selected from the sample and reevaluated by the same as well as a second observer. Inter and intra-examiner agreement was determined using Cohen's Kappa coefficient (nonparametric test). Regression Analysis was carried out taking age as a dependent variable $(\mathrm{Y})$ and degree of fusion (open $=0$, semi closed $=1$, closed with visible scar $=2$, closed with no visible scar $=3$ ) as an independent variable $(\mathrm{X})$ for the whole sample and in both sexes separately. The following statistical measures were calculated for all studied variables: minimum age, maximum age, mean with standard deviation. The Pearson correlation coefficient between variables in both sexes was calculated. The analyses were performed on the entire group and separately for males and females. All statistical analyses were performed using SPSS for Windows version 17 (statistical package for social science, Chicago, Illinois, USA).

\section{Results}

The sample included 217 subjects (121 males and 96 females) whose ages ranged between 15 and 25years. Regarding the age distribution of the sample population there was no significant 
difference in sex among different age groups ( $p$ value $>0.05$ and Pearson chi-square=2.814).

\section{Male subjects}

With regards to male subjects, 13 cases had open suture with a mean age of $16 \pm 1.53$ years, twenty cases had semi-closed suture with a mean age of $18.5 \pm 2.54$ years. In the group with semiclosed suture, twenty-five male cases had closed suture with persistent scar their mean age was $21.32 \pm 2.21$ years. Furthermore, sixty-three cases had closed suture without any visible scar. In this group the mean age was $21.78 \pm 2.94$ years. There was a significant difference in SOS stage among different age groups $\left(\mathrm{p}<0.000^{*}\right)$ (Table $1 \&$ Figure 1).

One-way ANOVA showed significant difference between age and suture closure in male group $\left(\mathrm{P}<0.001^{*}\right)$. Spearman's correlation ratio coefficient showed linear correlation between age and suture closure $\left(\mathrm{P}<0.001^{*}\right)$. Regression analysis was carried out taking age as a dependent variable $(\mathrm{Y})$ and degree of fusion (open $=0$, semi-closed $=1$ closed without $\mathrm{scar}=2$ and closed with $\mathrm{scar}=3$ ) as an independent variable $(\mathrm{X})$. Linear regression gave the following formula for age prediction: $\mathrm{Y}=14.905+1.788 \times \mathrm{X}(\mathrm{R} 2=0.335)$. Linear regression parameters for prediction of age in male subjects by Spheno-occipital suture closure status are shown in (Table 2). Thus the mean age of male subjects with open Spheno-occipital suture was 16years (with 95\% confidence interval 13.4-16.4years). The mean age of male subjects with semi-closed Spheno-occipital suture was 18.5 years (with $95 \%$ confidence interval 17.2-20.7years). In the male subjects with closed spheno-occipital suture with persistent scar the mean age was 21.32 (with 95\% confidence interval 20.0-23.6years). Also the mean age of male subjects with closed spheno-occipital suture without any visible scar was 21.78years (with 95\% confidence interval 20.4-24.0years).

\section{Female subjects}

With regard to female subjects, 3 cases had open suture, their mean age was $15 y e a r s$ and nine cases had semi-closed suture with mean age $20 \pm 2.35$ years. Moreover, sixteen female cases had closed suture with persistent scar. In this group, the mean age was $21.56 \pm 2.31$ years and sixty-eight cases had closed suture without any visible scar with a mean age of 20.41 \pm 3.24 years (Table $3 \&$ Figure 2).

One-way ANOVA showed a significant difference between age and suture closure in the female group $\left(\mathrm{P}<0.001^{*}\right)$. Spearman's correlation ratio coefficient showed linear correlation between age and suture closure $\left(\mathrm{P}<0.001^{*}\right)$. Regression analysis was carried out taking age as a dependent variable $(\mathrm{Y})$ and degree of fusion (open $=0$, semi-closed $=1$ closed without $s c a r=2$ and closed with $s c a r=3$ ) as an independent variable $(\mathrm{X})$. Linear regression gave the following formula for age prediction: $\mathrm{Y}=18.614+0.633 \times \mathrm{X} \quad(\mathrm{R} 2=0.025)$. Linear regression parameters for prediction of age in female subjects (weighted by age) by Spheno-occipital suture closure status are shown in Table 7. Thus the mean age of female subjects with open Spheno-occipital suture was 15 years (with $95 \%$ confidence interval 14.5-15.8years). The mean age of female subjects with semi-closed Spheno-occipital suture was 20years (with 95\% confidence interval 19.5-20.8years). In the female subjects with closed spheno-occipital suture with persistent scar the mean age was 21.56 (with 95\% confidence interval 21.1-22.4years). Also the mean age of female subjects with closed Spheno-occipital suture without any visible scar was 20.41 years (with $95 \%$ confidence interval 20.0-21.2years) (Table 4).

Regression analysis was carried out for the whole sample (combined male and female sample) taking age as a dependent variable (Y) and degree of fusion (open $=0$, semi-closed $=1$ closed without scar $=2$ and closed with scar $=3$ ) as an independent variable $(X)$. Linear regression gave the following formula for age prediction: $\mathrm{Y}=15.988+1.348 \times \mathrm{X}$ $(\mathrm{R} 2=0.166)$. Linear regression parameters for prediction of age in combined male and female subjects by Sphenooccipital suture closure status are shown in (Table 5).

Intra-examiner testing revealed slight differences when the same observer scored a series of 30 images with a 1 month time difference. There were only six instances where scores did not completely agree ( $80 \%$ agreement), and these differed by only one stage. Inter-examiner testing displayed a slightly lower degree of reliability with seven different readings of only one stage $(76.67 \%$ agreement). Cohen's Kappa measure of agreement gave a figure of 0.729 for intra-examiner testing and 0.678 for inter-examiner testing. These values represent a good agreement and demonstrate that the stages of closure for the spheno-occipital synchondrosis are distinct and easily interpreted. These results are displayed in Table 6 .

A midline ossification center within the sphenooccipital synchondrosis and or additional symmetric ossification centers on either side of the midline center were observed in $12.9 \%$ of cases $(28$ of 217 subjects). The percent of cases with ossification center was $81.25 \%$ (13 out of 16 cases) in those with stage $0,51.72 \%$ ( 15 out of 29 cases) in those with stage 1 and almost no ossification centers were observed in stages $2 \& 3$ (Table 7).

Table I Descriptive means of age in males by spheno-occipital synchondrosis closure status.

\begin{tabular}{llllllll}
\hline SOS Stage & $\begin{array}{l}\text { Mean(age) in } \\
\text { years }\end{array}$ & $\begin{array}{l}\text { Std. } \\
\text { deviation }\end{array}$ & Minimum & Maximum & Range & $\begin{array}{l}\text { Std. error of } \\
\text { mean }\end{array}$ & $\begin{array}{l}\text { Number } \\
\text { Open }\end{array}$ \\
16 & 16 & 1.528 & 15 & 20 & 5 & 0.424 & 13 \\
Semi closed & 18.5 & 2.544 & 15 & 23 & 8 & 0.569 & 20 \\
Closed with Scar & 21.32 & 2.212 & 16 & 24 & 8 & 0.442 & 25 \\
Closed without Scar & 21.78 & 2.937 & 16 & 25 & 9 & 0.37 & 63 \\
Total & 20.52 & 3.248 & 15 & 25 & 10 & 0.295 & 121 \\
\hline
\end{tabular}

*ANOVA test There was a significant difference in the mean age between different SOS stage groups ( $\mathrm{v}$ value $<0.000 *, F=33.563$ ). 
Table 2 Linear regression parameters for prediction of age in males by spheno-occipital synchondrosis closure status.

\section{Coefficients ( Dependent Variable:Age by years)}

\begin{tabular}{|c|c|c|c|c|c|c|c|c|}
\hline \multirow[t]{2}{*}{ Model } & & \multicolumn{2}{|c|}{$\begin{array}{l}\text { Unstandardized } \\
\text { coefficients }\end{array}$} & \multirow{2}{*}{$\begin{array}{l}\text { Standardized } \\
\text { coefficients } \\
\text { Beta }\end{array}$} & \multirow[t]{2}{*}{$\mathbf{T}$} & \multirow[t]{2}{*}{ Sig. } & \multicolumn{2}{|c|}{$\begin{array}{l}95 \% \text { Confidence interval } \\
\text { for B }\end{array}$} \\
\hline & & B & Std.error & & & & Lower bound & $\begin{array}{l}\text { Upper } \\
\text { bound }\end{array}$ \\
\hline \multirow[t]{2}{*}{1} & Constant & 14.905 & 0.765 & & 19.49 & 0 & 13.39 & 16.419 \\
\hline & SOS Status & 1.788 & 0.231 & 0.579 & 7.741 & 0 & 1.331 & 2.246 \\
\hline
\end{tabular}

Table 3 Descriptive means of age in females by spheno-occipital synchondrosis closure status.

\begin{tabular}{|c|c|c|c|c|c|c|c|}
\hline SOS Stage & Mean & Std. Deviation & Minimum & Maximum & Range & Std. Error of Mean & Number \\
\hline Open & 15 & 0 & 15 & 15 & 0 & 0 & 3 \\
\hline Semiclosed & 20 & 2.345 & 16 & 22 & 6 & 0.782 & 9 \\
\hline Closed with Scar & 21.56 & 2.308 & 17 & 24 & 7 & 0.577 & 16 \\
\hline Closed without Scar & 20.41 & 3.238 & 15 & 25 & 10 & 0.393 & 68 \\
\hline Total & 20.4 & 3.14 & 15 & 25 & 10 & 0.321 & 96 \\
\hline
\end{tabular}

There was a significant difference in the mean age among SOS stages ( $\mathrm{p}$ value $<0.001 *, \mathrm{~F}=5.148$ ).

Table 4 Linear regression parameters for prediction of age in females by spheno-occipital synchondrosis closure status.

Coefficients ( Dependent Variable:Age by years)

\begin{tabular}{|c|c|c|c|c|c|c|c|c|}
\hline \multirow[t]{2}{*}{ Model } & & \multicolumn{2}{|c|}{$\begin{array}{l}\text { Unstandardized } \\
\text { Coefficients }\end{array}$} & \multirow{2}{*}{$\begin{array}{l}\text { Standardized } \\
\text { Coefficients } \\
\text { Beta }\end{array}$} & \multirow[t]{2}{*}{$\mathbf{T}$} & \multirow[t]{2}{*}{ Sig. } & \multicolumn{2}{|c|}{$\begin{array}{l}95 \% \text { Confidence interval } \\
\text { for B }\end{array}$} \\
\hline & & B & Std.error & & & & $\begin{array}{l}\text { Lower } \\
\text { bound }\end{array}$ & $\begin{array}{l}\text { Upper } \\
\text { bound }\end{array}$ \\
\hline \multirow[t]{2}{*}{ I } & Constant & 18.614 & 0.33 & & 56.488 & 0 & 17.967 & 19.26 \\
\hline & SOS Status & 0.633 & 0.09 & 0.157 & 7.011 & 0 & 0.456 & 0.81 \\
\hline
\end{tabular}

Table 5 Linear regression parameters for prediction of age in the whole sample by spheno-occipital synchondrosis closure status.

\begin{tabular}{|c|c|c|c|c|c|c|c|}
\hline \multirow[t]{2}{*}{ Model } & \multicolumn{2}{|c|}{$\begin{array}{l}\text { Unstandardized } \\
\text { Coefficients }\end{array}$} & \multirow{2}{*}{$\begin{array}{l}\text { Standardized } \\
\text { Coefficients } \\
\text { Beta }\end{array}$} & \multirow[t]{2}{*}{$\mathbf{T}$} & \multirow[t]{2}{*}{ Sig. } & \multicolumn{2}{|c|}{ 95.0\% Confidence Interval for B } \\
\hline & B & Std. Error & & & & Lower Bound & Upper Bound \\
\hline I (Constant) & 15.988 & 0.713 & & 22.432 & 0 & 14.583 & 17.393 \\
\hline SOS_CODED & $\mathrm{I} .348$ & 0.206 & 0.407 & 6.54 & 0 & 0.941 & $\mathrm{I} .754$ \\
\hline
\end{tabular}

Table 6 Observer agreement.

\begin{tabular}{lll}
\hline & Intra-examiner & Inter-examiner \\
\hline No. of Cases & 30 & 30 \\
Mean of difference & 0 & 0 \\
SD of difference & 0.643 & 0.587 \\
Score Agreement (\%) & $80 \%$ & $76.67 \%$ \\
Cohen's Kappa (K) & 0.729 & 0.678 \\
\hline
\end{tabular}

Citation: Barrany UMIE, Ismail MMED, Mohamed MA, et al. Estimation of Age from spheno-occipital synchondrosis closure using computed tomography in Yemen. Forensic Res Criminol Int J. 20I5; I (I): I8-25. DOI: I0.15406/frcij.20I5.0I.00005 
Table 7 State of ossification centers in spheno-occipital synchondrosis.

\begin{tabular}{llllll}
\hline \multirow{2}{*}{ Stage } & \multicolumn{2}{l}{ State of Ossification Centers } & \multirow{2}{*}{ Total } \\
\cline { 2 - 4 } & No & $\%$ & No & $\%$ & \\
\cline { 2 - 4 } & Nosent & \multicolumn{3}{c}{ Absent } & \\
\cline { 2 - 4 } Stage 0 & 13 & 81.25 & 3 & 18.75 & 16 \\
Stage 1 & 15 & 51.72 & 14 & 48.28 & 29 \\
Stage 2 & 0 & 0 & 41 & 100 & 41 \\
Stage 3 & 0 & 0 & 131 & 100 & 131 \\
Total & 28 & 12.9 & 189 & 87.1 & 217 \\
\hline
\end{tabular}

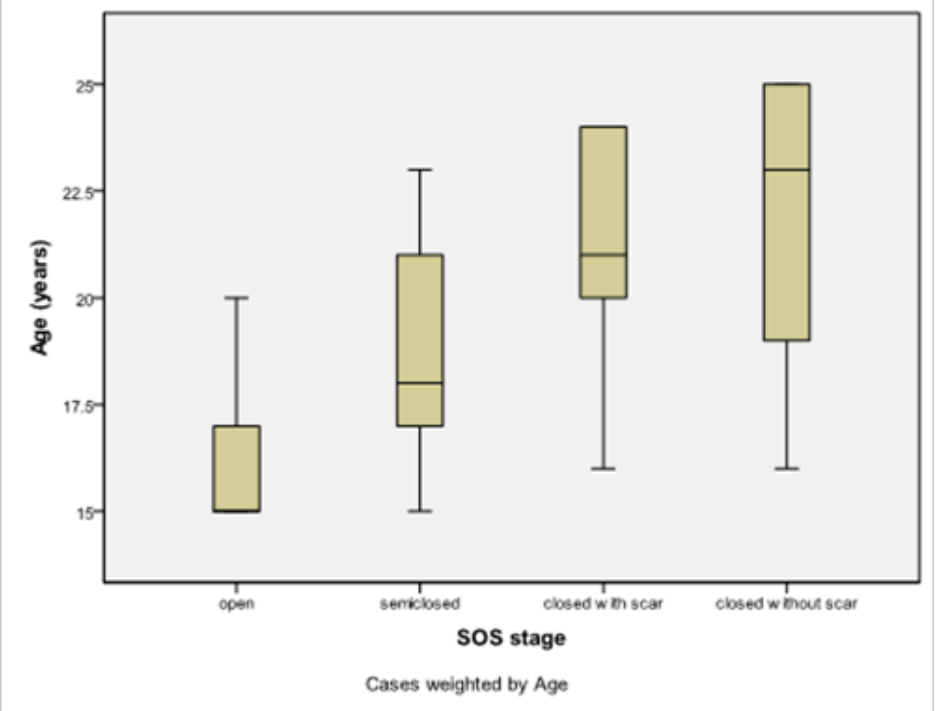

Figure I Box-plot of spheno-occipital synchondrosis status in male subjects by age.

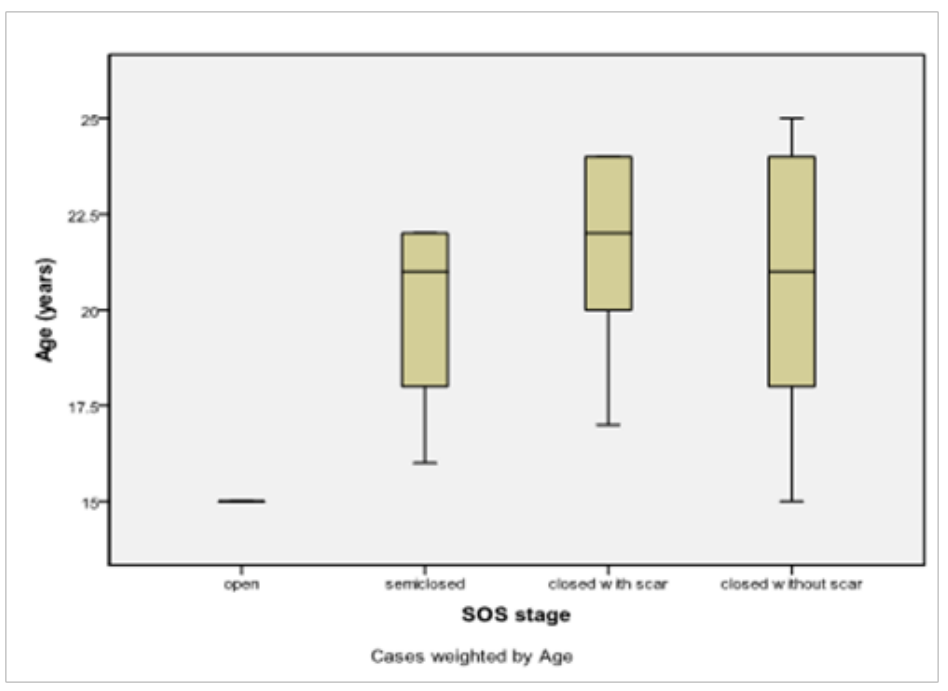

Figure 2 Box-plot of spheno-occipital synchondrosis closure status in females. 


\section{Discussion}

Forensic Age Estimation (FAE) defines an expertise in forensic medicine which aims to define, in the most accurate way, the 6 chronological age of person of an unknown age involved in judicial or legal proceedings. The term "estimation" defines more precisely than other as "diagnosis" the real limits inherent to this expertise. The state of the art in FAE is such that nowadays there is no medical test or a group of tests that absolutely and accurately let us know the exact chronological age of a human being. ${ }^{8}$ During the last fewyears, a growing section of forensic anthropology concerns the study of living individuals and, in particular, the problem of identifying and estimating age in living young adults for legal purposes. ${ }^{9}$ Verified documentation of the date of birth is the only way of determining the exact age of an individual. However, in subjects who do not possess proper identification documents, it is of the utmost importance to verify whether these persons should be accepted as juveniles or adults. This is so not only in criminal prosecutions but also in civil hearings, including determination of refugee status. Although age thresholds change according to country of interest, in most countries, the age of relevance to criminal liability ranges between 14 and 18 years. ${ }^{10}$ Nowadays, a new research focuses on the development of multifactorial methods for age estimation, whereby a combination of methods (or anatomical growth markers) can provide the most accurate age estimate with the smallest possible error. The difficult task for forensic researchers assessing age for the purposes of the legal system is still to convey accurately the degree of error inherent in whatever method is used and to clarify the likelihood that an individual below 18 years of age will be wrongly classified as an adult New techniques have been developed for older teenage individuals, which can provide age estimates with substantially narrower age ranges at the $95 \%$ confidence level. ${ }^{9}$ The spheno-occipital synchondrosis was chosen as an age marker of interest since past researches suggested that there is considerable variation in the time of closure which required further investigation to assess its suitability as an age estimation tool for a certain age group. Past research has demonstrated that population specific data are required in order to obtain the most accurate estimations of age. ${ }^{2}$ Furthermore, there has also been no study of the spheno-occipital synchondrosis and its closure sequence in the Yemeni population. In this cross-sectional study, the relationship between spheno-occipital synchondrosis closure and chronological age is analyzed. The advent of multi-slice computed tomography in the forensic field has enabled researchers to examine skeletal age markers with a greater degree of detail than has previously been possible. Most research to date using this imaging modality has been confined to slice thicknesses of $3-7 \mathrm{~mm}$, which whilst better than conventional radiography, does not provide sufficient resolution to enable accurate separation of growth stages for areas such as the medial clavicle and the spheno-occipital synchondrosis. ${ }^{11}$ This study utilized $4.8 \mathrm{~mm}$ slices of the area of interest, which provides high resolution images that allow accurate separation into the various growth stages. Early radiological observations ${ }^{12,13}$ regarding the ossification of the synchondrosis vary from puberty to the third decade. After giving reference to several books, Mckern T \& Stewart $\mathrm{T}^{14}$ came to the conclusion that there was no agreement on the age at which complete fusion occurs between the two bones. Several other investigators suggest that the synchondrosis stays open throughout childhood and early adolescence and states fusion times that lie between $18-25$ years. ${ }^{6,15-17}$ This would suggest that there may be significant inter-population differences related to ancestry for this development site and highlights the need for population specific data. Kahana $\mathrm{T}$ et al. ${ }^{18}$ found no correlation between chronological age and the closure degree of the synchondrosis in males, although in females they found it a possible reliable indicator of age but they had a small sample comprising of 21 females. Many studies show variations in the time of SOS closure which raises the issue of inter population variation. Another possible reason for this variation in fusion between studies is the different methods of analysis used by different researchers. Dry skulls, histological sections, conventional radiography, and CT imaging may possibly be interpreted differently. A synchondrosis which looks completely closed in a dry skull may not be so when a high resolution CT scan of the same skull is viewed. The same applies to conventional radiography images, which for this particular age marker are very difficult to interpret due to the difficulties involved in aligning the X-ray beam with the synchondrosis, and the large number of overlying structures which can confuse interpretation of the image. ${ }^{2}$ In this cross-sectional study, a large sample of both sexes was examined. It is apparent that progressive closure of the synchondrosis is correlated with age. Our results showed that the closure degree of Spheno-occipital suture has a linear correlation with age. Mean ages of open, semi closed and closed suture groups were significantly different in both sexes. We examined the state of fusion of the SOS or basilar synchondrosis as a biological age indicator in a sample of 217 subjects of both sexes whose ages ranged between 15 and 25years. Our findings indicated that the stage of fusion of the SOS can be a useful indicator of age in male and female subjects, when estimating age of unknown individual, although further investigation on different ethnic population is recommended. Mean ages of open, semi-closed, closed sutures with scar and closed sutures without scar were 16, 18, 21.32 and 21.78years in males, and 15, 20, 21.56 and 20.41 in females, respectively. Seemingly, their difference was significant $(\mathrm{p}<0.001 *)$. Complete fusion (closed) was seen at 16 year olds or above in males and 15 year olds or above in females. Spearman's correlation ratio coefficient showed a linear correlation between age and suture situation in both sexes ( $r$ ho $=0.509, \mathrm{P}<0.000 *$ in males and rho $=0.080, \mathrm{P}<0.000 *$ in females). In male subjects when the suture is closed (with or without scar), age is 16years or above and when the suture is open or semiclosed, age is 23 years or below. Males transition from closing to close at 24years. In female subjects when the suture is closed (with or without scar), age is 15 years or above and where the suture is open or semi-closed, age is 22years or below. Females transition from closing to close at 23years. In the males, partial fusion was seen at 15 years while a complete fusion was noticed at $16 y e a r s$ in $25 \%$ of the subjects. The age of a boy showing complete fusion should be 16years or above. If there is no fusion or partial fusion he should be below 24 years as complete fusion is seen in all male subjects at 24 years. In females, the earliest partial fusion was noted at $16 y e a r s$ and complete fusion was present at 15 years in $62.5 \%$. All female subjects showed complete fusion at 23years. The minimum age of a girl showing complete fusion should be 15years; if no fusion or partial fusion is seen, her age should be below 23years. The small number of 15 -yearold females may not represent a true sampling of this age group as all eight individuals at this age were either stage 0 or 3 , whereas the same age group in males displayed greater variation, with $87.5 \%$ \& $12.5 \%$ of the cases was in stage $0 \& 1$ respectively. By age 21 years in males no individual score was less than 1 , with a progressive increase in the number of individuals scoring 2 and then 3 as the fusion scar became less apparent over time. By age 23years in females no individual score was less than 2 , with a progressive increase in the number of individuals scoring 3 as the fusion scar completely disappear at the age of 25 . The current study demonstrated consistency with studies of 
Akhlaghi $\mathrm{M}$ et al., ${ }^{6}$ in the timing of fusion particularly in male subjects (Table 8). This study also demonstrates some consistency with several other researchers in the timing of fusion. ${ }^{15,19-21}$ Some authors stated that development in females is earlier than males; our study was compatible with such studies but in contrast with Bassed R et al., ${ }^{2}$ in which there was no statistical difference between the sexes after the age of 16years. Detailed comparison of time of spheno-occipital synchondrosis closure in our study with different studies is shown in Table 8. The present results indicated that, in general, the observer agreement is good for both intra and inter-observer variability
(Cohen's Kappa (K): $0.729 \& 0.678$ respectively). The results of the inter- and intra-examiner error testing revealed that scoring this age marker is reliable and reproducible both with one observer, and also between different observers. There were very few differences between examiners, and no instances of greater than one stage scoring discrepancy. The differences that did occur resulted from cases where the synchondrosis could be classified as being in between two stages, and therefore more difficult to assign to a particular stage. Results of other studies utilizing the same scoring system but different examiners will therefore be comparable.

Table 8 Time of Spheno-Occipital Synchondrosis Closure in our Study Compared with Different Studies.

\begin{tabular}{lll}
\hline Current Study, 2012 (Yemeni Subjects; CT scan): & \\
\hline SOS Stage * & Males & Females \\
Stages 0-1 & $\leq 23$ & $\leq 22$ \\
Stages 2- 3 & $\geq 16$ & $\geq 15$
\end{tabular}

*SOS Stages: 0: Open, I:Semi-closed, 2: Closed with scar, 3: Closed without scar.

$\begin{array}{lcc}\text { Akhlaghi, et al. }{ }^{6} \text { (Iranian Subjects; Direct Inspection): } & \\ \text { SOS Stage* } & \text { Males } & \text { Females } \\ \text { Stages } 0-1 & \leq 21 & \leq 13 \\ \text { Stages } 2 & \geq 15 & \geq 12\end{array}$

*SOS Stages: 0: Open, I: Semi-closed, 2: Closed.

Sahni, et al. ${ }^{21}$ (Indian Subjects; Direct Inspection, X- ray \& CT scan):

SOS Stage*

Stages 0-1

Stages 2

*SOS Stages: 0: Unfused, I: Partially fused, 2: Completely fused.

\section{Acknowledgments}

None.

\section{Conflicts of interest}

The author declares that there are no conflicts of interest.

\section{References}

1. Shetty U. Macroscopic study of cranial suture closure at autopsy for estimation of age (thesis submitted to the University of Delhi, 2008, for MD in Forensic Medicine). Anil Aggrawal's Intern J Forensic Med \& Toxicol. 2009; 10(2).

2. Bassed RB, Briggs C, Drummer OH. Analysis of time of closure of the spheno-occipital synchondrosis using computed tomography. Forensic Sci Int. 2010;200(1-3):161-164

3. Bokariya P, Chowdhary DS, Tirpude BH, et al. A Review of the Chronology of Epiphyseal Union in the Bones at Knee and Ankle Joint. $J$ Indian Acad Forensic Med. 2011;33(3):258-260.

4. Marco T, Mazzarini L, Fabrizzi G, et al. Applicability of Greulich and Pyle method for age assessment in forensic practice on an Italian sample. Int $J$ Legal Med. 2011;125(3):411-416.
5. Iscan YM. Progress in forensic anthropology: the 20th century. Forensic Sci Int. 1998;98(1-2):1-8.

6. Akhlaghi M, Taghaddosinejad F, Sheikhazadi A, et al. Age-at-death estimation based on the macroscopic examination of Spheno-occipital sutures. J Forensic Leg Med. 2010;17(6):304-308.

7. Rajan RA, Swindells MG, Metcalfe JE, et al. Can orthopaedic clinicians learn to read skeletal bone age? An inter- and intra-observer study between specialties. J Child Orthop. 2011;5(1):69-72.

8. Schmeling A, Garamendi P, Prieto J, et al. Forensic Age Estimation in Unaccompanied Minors and Young Living Adults. In: Forensic MedicineFrom Old Problems to New Challenges. 2011;78-81.

9. Cameriere R, Cingolani M, Giuliodori A, et al. Radiographic analysis of epiphyseal fusion at knee joint to assess likelihood of having attained 18 years of age. Int J Legal Med. 2012;126(6):889-899.

10. Aynsley-Green A. Unethical age assessment. Br Dent J. 2009;206(7):337.

11. Mühler M, Schulz R, Schmidt S, et al. The influence of slice thickness on assessment of clavicle ossification in forensic age diagnostics. Int J Legal Med. 2006;120(81):15-17.

12. Caffey J. Paediatric X-ray Diagnosis. The Year Book Publishers Inc, Chicago. 1956;23(6):215. 
13. Pendergrass E, Schaeffer J, Hopes P. The Head and Neck in Roentgen Diagnosis. Surgery. 1940;8(6):1079-1080.

14. Mckern T, Stewart T. Skeletal Age Changes in Young American Males, Technical Report No. E.P. Environmental Protection Research Division. $1957 ; 25$.

15. Soames R. Gray's Anatomy. (38th edition). Churchill Livingstone publisher. 1995;585.

16. Madeline LA, Elster AD. Suture closure in the human chondrocranium: CT assessment. Radiology. 1995;196(3):747-756.

17. Mann SS, Naidich TP, Towbin RB, et al. Imaging of postnatal maturation of the skull base. Neuroimaging Clin N Am. 2000;10(1):1-21.
18. Kahana T, Birkby WH, Goldin L, et al. Estimation of age in adolescentsthe basilar synchondrosis. J Forensic Sci. 2003;48(3):504-508.

19. Ford E. Growth of human cranial base. Am J Orthod. 1958;44(7):498-506.

20. Trotter M, Peterson, R. In: Barry J. Morris' Human Anatomy. (12th edition). McGraw-Hill Book Company. 1966;187.

21. Sahni D, Jit I, Neelem Suri S Time of fusion of the basisphenoid with the basilar part of the occipital bone in northwest Indian subjects. Forensic Sci Int. 1998;98(1-2):41-45. 